\title{
Effectiveness of Moodle in student's independent work
}

\author{
Yana Gudkova*, Svetlana Reznikova, Maria Samoletova, and Elena Sytnikova \\ Southern Federal University, Rostov-on-Don, 344006, Russia
}

\begin{abstract}
Moodle is massively used as an essential component of blended-learning courses or mainly incorporated in traditional offline classes. The present research was aimed to investigate the effectiveness of integrating Moodle into student's independent study within the framework of EFL course delivered online at Southern Federal University. Both qualitative and quantitative approaches were used, questionnaires being the main data collection techniques. The results have showed that Moodle helps students to revise and better understand the material studied in class. It has also been found that Moodle has facilitated student-centered learning allowing students to complete tasks anywhere and anytime. Moreover, it has made course administration easier and helped to reduce the time of delivering instruction and getting the real-time analytics. In addition, the students have stated that interactive and multimedia materials encourage their active involvement in learning and retained motivation. Both students and instructors express positive opinions towards learning English via Moodle.
\end{abstract}

\section{Introduction}

Independent study is one of the most significant elements of the learning process in higher education. Approaches to its organization and control of learning results are fundamentally changing due to the transition to a new system of education: recently there has been a significant increase in the importance of the quality of higher education. Caused by the spread of COVID-19, there was a sudden need to move courses online at all kinds of educational establishments. Traditional classroom learning disappeared along with wellestablished educational processes and academic staff faced the challenges of distance learning.

Obviously, many of the practices that are traditionally used in face-to-face learning process can be adapted and applied in the online context. However, incorporation of technology provides additional factors in terms of acquiring new learning experiences, which implies a greater deal of student engagement and their independent learning [1].

It should be taken into account that first-year students tend to have weak skills of independent work. In this regard, it is necessary to organize students' independent work by implementing the indispensable control over its results and monitoring the learning process itself. Nowadays, it is becoming physically impossible to organize and monitor the learning

\footnotetext{
* Corresponding author: Yanag16@rambler.ru
} 
activities of each student using traditional classroom methods. Simultaneously, it is necessary to optimize the learning process without losing its quality.

In accordance with the federal state standard of the new generation $3++$, the implementation of the educational program requires the access to the digital educational environment. E-learning platforms such as WebCT, Blackboard, Moodle, Google Classroom, etc. are one of the key tools in distance education today. They offer valuable instruments that provide the organization of online courses, their maintenance, administration of the learning process and evaluation of the student's progress and feedback.

According to Suppasetseree and Nutprapha [2], Moodle is a widely used tool in technology facilitation to transfer language teaching and learning. Moodle is a license free open-source software platform that involves e-learning in ESL and EFL. It is stressed that in terms of instruction, Moodle can be used to create online courseware, which provides opportunities for interaction and communication between students and teachers.

Shi [3] considers that Moodle enables the content management (courses, homework) and it allows for both synchronized (by chat or videoconference) and non-synchronized (forum, message, blog.) collaboration. Moreover, it can be successfully used to manage the students that applied for the course.

Furthermore, Boškovi et al. [4] highlight the intuitive navigation of Moodle that allows students to understand how to use this system in a short training. It is also important that using Moodle for teaching and learning the English language corresponds to the advantages of distance learning education in general and students themselves have the opportunity to learn English in an interesting way, which is different from what they are used to.

Jeong [5] concludes that Moodle learning environment is an effective method for teaching English as a foreign language in university. The benefit of Moodle is that it fully exploits learner-centered approach.

Dofs and Hobbs [6] believe that Moodle develops learners' learning autonomy, allowing them to learn a foreign language by sections (grammar, vocabulary, listening, reading and writing) independently without a teacher's guidance. In addition, Moodle gives students the opportunity to assess their level of language proficiency and compare it with previously obtained grades. Being an open online system, Moodle is constantly updated due to the collective efforts of educators and experts. Therefore, the utilization of Moodle can be effective in promoting learner autonomy as well as in supporting collaboration and learnercentered learning environment.

With Moodle, teachers also use various technology-driven teaching techniques to get their students engaged in a variety of learning contents.

However, it should be noted that Moodle is massively used as an essential component of blended-learning courses or mainly incorporated in traditional offline classes. This research is aimed at considering the effectiveness of integrating and implementing Moodle in student independent work in terms of online learning of English. The target audience of this study is the first-year students at Southern federal university whose English classes are limited to online environment only.

While evaluating the effectiveness of Moodle we should take into consideration how well it can individualize and differentiate the learning process; meet the requirements of the subject content and teaching methods as well as various organizational forms; structure and characterize the knowledge and skills obtained. In addition, it is vital to increase motivation and knowledge acquisition.

\section{Materials and Methods}




\subsection{The Study}

As part of the English as a Foreign Language (EFL) course requirements, first-year undergraduate students at Southern Federal University (SFedU, Rostov-on-Don, Russia) were offered to use Moodle online learning management system (Moodle OLMS). Listening, reading, vocabulary and grammar modules for levels A1 to $\mathrm{C} 1$ in accordance with the Common European Framework of Reference (CEFR) were developed to complement the entire EFL course. The research was conducted in the fall semester of 2020-2021 academic year. The students could use the platform any place and time of their convenience to fulfil the set of the suggested materials for their independent work within the course of the English language. The users had taken a placement test incorporated in the Moodle platform and based on its results they were divided into the study groups according to their level of proficiency before having access to the main course content and were assigned to specific language materials complementing the course. The number of hours designed for the independent work constituted 54 hours irrespective of their language proficiency level. They took 3 progress tests and an achievement test in the middle and at the end of the term respectively to measure their progress and overall achievement. The practices of learners were surveyed at the end of the semester using the progress test.

\subsection{Research Methodology}

A case study method has been implemented in this research. This is one of the research methods that can both use a qualitative and quantitative approach. This combination of quantitative and qualitative approaches complements each other and provides complete analysis [7]. As our study was focused on both statistical data of the questionnaires and the qualitative assessment of the interviews, both the qualitative and quantitative approaches in gathering and presenting the information were used. The pre-developed modules had some features and had already been pre and pilot tested in advance before the beginning of the course. The features of the proposed modules on Moodle OLMS will be given further.

An essential step of the study was to expose and encourage students to use Moodle platform for their independent work. This means that majority or if not, a considerable percentage of their projects and assignments for the independent work were posted and had to be submitted via Moodle. Their assignments would be taken up and checked on automatically with the further feedback from their instructor. At the end of the term all students took a survey that they answered using a rating scale (ranging from "agree" to "disagree"). Each student's response to a certain question had a corresponding value or rating of the impact of the Moodle-based activities on the English language learners. Once all the interviewees finished responding the questionnaire, the next step was to compile and tally the results followed by the analysis. By the end of the analysis, it became possible to get a number that indicates how big or small the impact of using the Moodle platform as an online learning management system for independent work had been for the students. All the students did not have any prior experience in using Moodle and were at the different CEFR levels. Two types of surveys were used at the end of the term. The first survey was provided online via Moodle platform for the students to provide the answers. The second survey and questionnaire were developed by using Microsoft Word and sent to the course instructors. The opinions and responses of these two groups were the focus of the discussions and analysis as to the effects and impacts of using Moodle as an e-learning tool for organizing students' independent work at SFedU. 


\subsection{Limitations and Scope of the Study}

While it is important to conduct a comprehensive study, as it is needed, the research restricted the study to a target population and focused on making accurate conclusions. However, there were some constrains that have been noted in this study, namely, the limited number of participants - 270 students and 7 instructors. Naturally, a smaller population would negatively affect the overall reliability of the results and findings. On the contrary, the present research involved more than 200 people, which is typical for studies aimed at establishing the reliability and/or validity of a new standard of practice, or in this case, the use of Moodle platform in an English language learning course. Another major obstacle was the limited number of activities in which the usability and convenience were assessed.

\subsection{Moodle-based module features:}

- a range of assignments (listening, writing, reading, video watching and filming, audio recording)

- links to grammar and vocabulary external resources (BBC Learning English, LearningApps.org, Quizlet, LiveWorksheets.com, Breaking News English)

- online multiple-choice quizzes

- instant messaging service for team member communication

- announcement system to be updated by the instructor

- online Moodle calendar for assignments and quizzes.

Since it was the first time for the students to deal with Moodle, they were given a detailed instruction on Moodle platform and the requirements for the individual work assignments. The instruction also included some basic information for the students to help them understand how to login to Moodle, use it, and complete the tasks. Also, the language instructor met the students online in Microsoft Teams and answered the questions or cleared up all confusions regarding the use of Moodle.

\subsection{Data Gathering and Analysis}

All the students and instructors took a survey upon the completion of 3 modules of the course. Both students and instructors were asked to rate 7 statements in a form of a rating scale (Tables 1, 2) in order to measure the effectiveness of the Moodle-based e-learning tool for conducting the individual work and to get the profound feedback. Additionally, the instructors were asked to fill in the questionnaire (Table 3) that consisted of 3-4 open-ended questions, so they had to be answered qualitatively. After all surveys had been completed, the results were interpreted and analyzed.

\section{Results}

In this section the results interpreting the effectiveness of Moodle for independent student's work are provided in Tables 1-3 and figures 1-2.

Table 1. Students' responses on the effectiveness of using Moodle in student independent work for learning English online

\begin{tabular}{|l|c|c|c|}
\hline Criteria & Agree & Uncertain & Disagree \\
\hline $\begin{array}{l}\text { Moodle allows you to address your specific } \\
\text { problem areas in language learning. }\end{array}$ & 152 & 103 & 15 \\
\hline
\end{tabular}




\begin{tabular}{|l|c|c|c|}
\hline $\begin{array}{l}\text { You can choose convenient time and place to } \\
\text { complete assignments and their order. }\end{array}$ & 250 & 7 & 14 \\
\hline $\begin{array}{l}\text { Materials presented in Moodle help to } \\
\text { consolidate the topics studied in class. }\end{array}$ & 264 & 6 & 0 \\
\hline Moodle provides a wide range of activities. & 163 & 27 & 80 \\
\hline Online chat in Moodle is very effective. & 229 & 8 & 33 \\
\hline $\begin{array}{l}\text { Activities are organized in a useful and } \\
\text { understandable way. }\end{array}$ & 268 & 0 & 2 \\
\hline $\begin{array}{l}\text { Multimedia materials in Moodle make learning } \\
\text { more interesting. }\end{array}$ & 270 & 0 & 0 \\
\hline
\end{tabular}

When asked if independent work via Moodle catered for their specific learning needs 152 respondents found Moodle helpful in terms of improving their problem areas. Over $84 \%$ (250 students) agreed that Moodle-based tasks helped them to be more organized and self-disciplined. About 3\% (7 students) admitted that they needed to improve their timemanagement skills, followed by $5 \%$ (14) who stated they failed to set time aside to complete the assignments on time. 264 students found that activities presented in Moodle facilitated revision and led to better understanding of the material studied in class. 163 students thought that the offered activities were diverse and focused on different language learning areas whereas 80 students indicated that there was not much variety in task activities. $85 \%$ of respondents felt comfortable communicating with their instructors and classmates online, with $12 \%$ indicating that online chats did not contributeto their learning progress. 268 respondents showed the resources and tasks were logical, well structured and easy to navigate. Only a small percentage of students reported difficulty in understanding what they had been expected to do. All respondents $(100 \%)$ stated that interactive and multimedia materials encouraged their active involvement in learning and retained motivation.

Table 2. Instructors' responses on the effectiveness of using Moodle in student independent work for learning English online.

\begin{tabular}{|l|c|c|c|}
\hline \multicolumn{1}{|c|}{ Criteria Agree } & Uncertain & Disagree \\
\hline $\begin{array}{l}\text { Moodle allows integrating many free } \\
\text { applications making study process } \\
\text { individualized and unique. }\end{array}$ & 6 & 1 & 0 \\
\hline $\begin{array}{l}\text { Moodle determines the best instructional } \\
\text { approaches or modifications needed for each } \\
\text { student. }\end{array}$ & 5 & 1 & 1 \\
\hline Moodle provides richer content to students. & 4 & 3 & 0 \\
\hline $\begin{array}{l}\text { Moodle makes use of different organizational } \\
\text { forms. }\end{array}$ & 7 & 0 & 0 \\
\hline Moodle enables active learning presented in Moodle & 5 & 2 & 0 \\
\hline Moodle provides a more systematic approach. & 6 & 0 & 1 \\
\hline $\begin{array}{l}\text { Multimedia materials presen } \\
\text { increase student's motivation. }\end{array}$
\end{tabular}

Most of the instructors $(85 \%)$ agreed that Moodle allowed posting various online resources in one instructional environment to supplement the main course material and facilitate student-centered learning. $71 \%$ of respondents indicated that the hierarchy of training activities presented in Moodle was built on the principle "from simple to complex", which provided clarity in the organization of training. The automatic check system ensured monitoring progress, evaluating each type of work, including the amount of time spent on their implementation and the number of attempts made. However, $29 \%$ considered that they 
were not able to give immediate feedback on students' results. A delayed or ineffective feedback was a real challenge. $60 \%$ of respondents surveyed stated that they had provided their students with much more diverse teaching materials in the form of interactive multimedia (images, animation, education games) content while $40 \%$ reported otherwise specifying that they had given their students the same range of content outside Moodle OLMS. All respondents indicated that the transition of independent work into an online format enabled them to organize their study using a large variety of assignments including written assignments, reflection papers, posters, monitoring quizzes, and chats. When asked about students' engagement in the learning process $100 \%$ of instructors stated it was enhanced via Moodle, which is primarily due to Moodle accessibility and variability of module materials. Students could study online whenever and wherever they wanted as well as be selective in their studies. All respondents saw the value of incorporating Moodle into their instruction in order to make sure that students do self-study outside the classroom on a regular basis, to ensure their exposure to appropriate and high-quality teaching materials that correspond the main course and the level of proficiency. $71 \%$ found that diverse interactive audio- and video content attracted students' interest in completing activities on the platform. Moreover, such combination allowed students to drill and revise material on time and in full extent, which made them more confident and active in classroom, while 29 $\%$ were uncertain.

Table 3. Open-ended questions for both students and instructors

\begin{tabular}{|l|l|}
\hline 1. & What activities do you find the most effective? \\
\hline 2. & What language skills did Moodle improve? \\
\hline 3. & What technical difficulties did you encounter? \\
\hline 4. & Did Moodle OLMS reduce your workload in online teaching/learning? \\
\hline 5. & Was the statistics provided in Moodle helpful when assessing the progress? \\
\hline 6. & How would you improve the independent study on Moodle platform? \\
\hline
\end{tabular}

What activities do you find the most effective?

Both the teachers $(86 \%)$ and the students $(80 \%)$ claimed that matching, filling in the gaps and tests were the most effective activities. The instructors found these formats to be the most convenient for uploading into Moodle platform and intuitively clear. The tests gave the students the chance to prepare for the progress tests and get higher marks. The overwhelming majority of students $(95 \%)$ also mentioned that video materials with explanation of grammar rules facilitated understanding grammar as it was presented in a more appealing form.

What language skills did Moodle improve?

As seen from Tables 4 and 5 grammar and vocabulary were marked as the most effective due to plenty of tasks and various forms for both practicing the skills and progress monitoring. The efficiency of Moodle-based vocabulary tasks was equally highly rated by the instructors $(33 \%)$ and the students $(32 \%)$ compared to grammar tasks $(36 \%$ and $27 \%$ respectively). This can be accounted for by the fact that the instructors correlated better performance at tests with the fulfilment of numerous grammar tasks. Listening tasks presented in Moodle were seen as not very productive (21\% and $23 \%$ respectively) in terms of skill development due to the abundance of publicly accessible listening activities presented on the Internet. Reading was marked as the least effective due to the fact that developing this skill is much more time-consuming process which requires the integral knowledge of grammar and vocabulary as well as comprehension practice. 


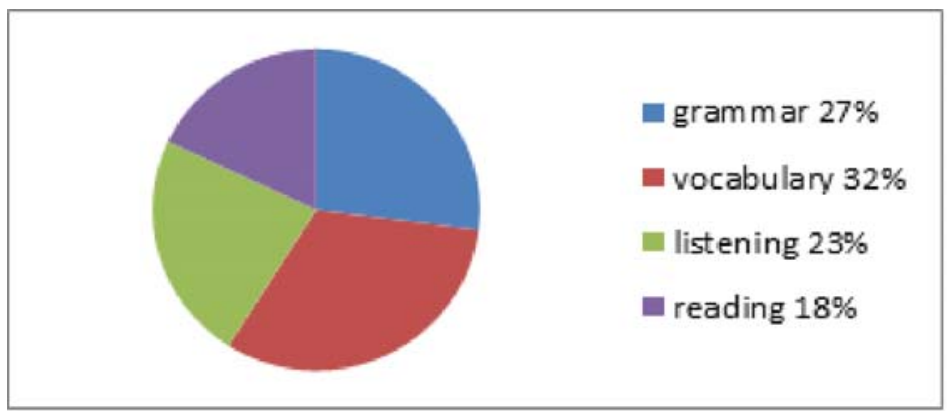

Fig. 1. Teachers' responses on skills development

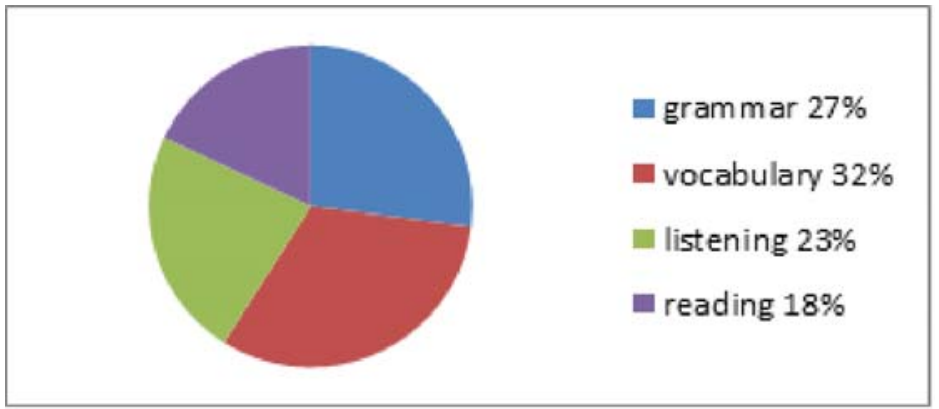

Fig. 2. Students' responses on skills developments

What technical difficulties did you encounter?

At least $10 \%$ of student population faced some technical issues such as the quality of connection, platform access problems and blackouts that led to the loss of partly completed test results. Besides, it was impossible to pause the test and save the results in the middle of the test. The instructors $(71 \%)$ have also emphasized that they required technical assistance to upload the tasks.

Did Moodle OLMS reduce your workload in online teaching/learning?

The students agreed that Moodle OLMS reduced their workload as the tasks were given beforehand thus providing the opportunity to spread the workload and to manage the time more efficiently. For the instructors $(100 \%)$ the availability of all resources on one platform and automated marking were undoubtedly the biggest benefits. However, preparing materials for uploading to Moodle significantly increased instructors' workload at the preparatory stage.

Was the statistics provided in Moodle helpful when assessing the progress?

All instructors $(100 \%)$ found the statistics extremely useful. It let them implement a more individual approach to giving the students personified feedback. About 55\% of the students stated that automated instant results gave the opportunity not only to see their progress but also to assess the preliminary results before writing the progress tests. The rest of the student population admitted that they paid little attention to statistical data.

How would you improve the independent study on Moodle platform?

Most respondents ( $86 \%$ of instructors and $83 \%$ of students) suggested including some project works to encourage collaboration between the students and tasks for practicing writing.

\section{Discussion}


The results indicate that Moodle certainly features a great number of positive aspects. Generally, students and instructors find learning and teaching the English language by Moodle platform easier, really efficient and productive, and with more advantages than disadvantages. As well as the findings of similar studies by Umek et al [11] the implementation of Moodle is marked with a statistically and numerically significant increase in students' skills development and overall performance.

It represents a modern and very convenient tool for English language learning. This platform enables students to organize their learning space and time independently and offers transparency, clear structure and effective self-evaluation. The data shows that students are satisfied with the opportunity to learn English in a new different but comfortable way. The results support the claims of Armstrong-Mensah et al. [12] that the majority of students indicated a preference for the asynchronous approach to online teaching. Their choice was mostly based on the fact that it gave them the ability to learn at their own pace and do course work when they were ready.

Due to the flexibility of Moodle, they access teaching materials at any comfortable time and from any suitable place. They have the opportunity of using multimedia instruments and applications, such video/audio-based or animated activities to practice their skills in an interactive manner.

In terms of skills, development the study demonstrates the Moodle is not difficult to use and most students learn how to use this platform relatively fast. Besides, Moodle provides additional time for studying the material thoroughly and considering possible answers.

On the other hand, it is worth mentioning that Moodle was not originally created as a tool for language learning [13]. Consequently, it is not surprising that it does not present the perfect model for online learning. In spite of the fact, it offers numerous advantages and advanced learning methods, it sometimes meets negative reactions of students and teachers involved in learning English as a foreign language.

Some technical difficulties (access to the Internet, stability of the network, slow response in case of many users connected to

Moodle, difficulties when opening or downloading specific types of files in certainbrowsers etc.) were identified and this was proved by the other researchers [14]. A number of students still can face the same obstacles and problems as their teachers - the lack of computer literacy and IT skills. Apart from this, students complain about the lack of personal contact and the inability to have access to their peers' profiles [15], i.e. about delayed interaction with their teachers. Therefore, it is not surprising that the overwhelming majority of both students and instructors would definitely find project works and collaborative writing useful and motivating.

Despite the fact that Moodle platform offers detailed instructions to teachers how to post and organize materials for English language learning, as well as to assess and mark posted tests, teachers should still possess an advanced level of computer literacy and have specific IT knowledge. They need special training to develop and upload materials into the platform, which is technically complicated and time-consuming. On the other hand, one of the long-term prospects of applying Moodle on a regular basis is that the time spent in a face-to-face learning environment will inevitably decrease.

The main limitations of the research can be attributed to both individual and external factors. The former is students' personal motivation in learning the language, their previous experience in using various multimedia tools for language learning, with the latter being the limited number of functions provided by the platform, its technological characteristics etc. These factors should be the subject of our further research in the near future.

\section{Conclusion}


According to the results obtained, Moodle appears an effective tool to organize, maintain and assess the independent work of undergraduate students. The application of the Moodle platform has shown a number of advantages over the traditional forms like accessibility of the materials, a wide range of interactive activities, the implementation of student-centered individual approach and sustainable motivation throughout the course. From the point of view of instructor, the platform has also demonstrated a number of benefits like more organized, unified and logical structure of the tasks for the independent work, economy of time and efforts for the marking and clear and straightforward analytics, which makes the assessment and feedback less time-consuming and more individual. Further, the negative experience can easily be eliminated by further experience in the use of the tool as well as overall better computer literacy of both students and instructors.

The authors would like to thank the English language instructors of the Department of English for Sciences at SFedU for sharing information about their work with students.

\section{References}

1. J. Gillett-Swan, Journal of Learning Design 1 (10), 20-21 (2017).

2. S. Suppasetseree, K. Nutprapha, International Journal of the Humanities 1, 29-46 (2010).

3. X. Shi, International Journal of Emerging Technologies in Learning 4 (11), 120-125 (2016).

4. V. Bošković, T. Gajić, I. Tomić, Proceedings of Singidunum University International Scientific Conference "SINTEZA 2014 - Impact of Internet on Business Activities in Serbia and Worldwide”, 480-483. (2014). Singidunum University, Belgrade.

5. K. Jeong, Journal of Theoretical and Applied Information Technology 18 (95), 48464852 (2017).

6. K. Dofs, M. Hobbs, Studies in Self-Access Learning Journal 1 (7), $72-83$ (2016).

7. M. Musingafi, B. Mapuranga, K. Chiwanza, S. Zebron, Journal of Education and Practice 18 (6), (2015).

8. I. Klimova, M. Melnichuk, P. Rostovtseva, Culture and Education 4, 262-265 (2019) (In Rus.)

9. C. Costaa, H. Alvelosa, L. Teixeiraa, The use of Moodle e-learning platform: a study in a Portuguese University, CENTERIS 2012 - Conference on ENTERprise Information Systems, pp.334-343, (2012).Elsevier BV.

10. H. Karala, A. Cebib. Social and Behavioral Sciences 46, 2073 - 2077 (2012).

11. D. Keržič, A. Aristovnik, N. Tomaževič, L. Umek, International Journal of Innovation and Learning 2 (21), 165-177 (2017).

12. E. Armstrong-Mensah, K. Ramsey-White, B. Yankey, S. Self-Brown, Frontiers in Public Health 8, 1-10 (2020).

13. N. Holiver, T. Kurbatova, I. Bondar, The International Conference on Sustainable Futures: Environmental, Technological, Social and Economic Matters 166, 1-6 (2021). https://doi.org/10.1051/e3sconf/202016610006, last accessed 2021/01/16.

14. P. Zoran M. Ivanovic, Ž. Mudrinski, T. Welzer, Informatica 37 (3), 221-230 (2013).

15. M. Hölbl, T. Welzer, L.N. Zlatolas, F. Sevcnikar, Student feedback experience and opinion using Moodle, Proceedings of the 22nd EAEEIE Annual Conference (EAEEIE), pp.1-4. (2011). IEEE, Maribor, Slovenia. 